muscular cöordination and power very much restored to arm; leg still almost motionless." My summary of the diagnosis reads: "The continued, prolonged nature of the case" (there was subnormal power in the limbs in the middle of July), "the evident absence of rnental disturbance of the higher centres-e.g, those of rational thought,-the implication of the tongue and eye, the gradual development of hemiplegia, the want of the peculiar 'heel dragging' in walking, and the slow, lengthened convalescence, negative such a supposition"-viz, a suggestion previously made of hysterical paralysis ; and-"We have here a history of interrupted brain function of the special centre of speech followed by hemiplegia of the right side ...... the left middle cerebral artery had been suddenly occluded, and the consequent train of symptoms indicative of impaired arrested function of the left frontal convolution, of the left corpus striatum, and convolutions in its vicinity, followed."

As illustrating what I esteem a still rarer condition in the puerperal, I would refer your readers to a case of left-sided hemiplegia associated with albuminuria and kidney affection. I believed the paralysis to be of reflex nature; the account is published in vol. ix., p. 122, of the Transactions of the Edinburgh Obstetrical Society. In this case paresis with aphasia and drowsiness came on, on April 26th, 1880 . Amaurosis had been noted on April 22 nd. A reference to the volume named will show a wholly dissimilar clinical history to the one quoted formerly. "Delivery on May 5th of living but weakly child; no eclampsia; return of muscular power to hand longest delayed. By middle of June patient recovered."

In connexion with the subsequent discussion, to which the late Dr. Angus Macdonald made a most invaluable contribution, he incidentally suggested (p. 192, vol. ix., Trans. Obstet. Soc.) the possibility of embolus or "sand grain" apoplexies as explanatory of the pathology. My friend Dr. Underhill was also inclined to accredit miliary aneurysms or embolism as a likely pathological explanation. Ny reply on the discussion touched on the further grounds which seemed to me to warrant a diagnosis of " reflex paralysis." The history of two other cases of puerperal aphasia in abstract, with an interesting post-mortem account extracted from the Allgemeine Medicin CentralZeitung (No. 33, 1879), will be found in the British Medical Journal, vol. ii. 1879 , p. 882 . In my paper previously mentioned, I remark: " Both seem to have been due to inAammation. .............. Dr. Lewandowski's case suggests encephalitis, and the other was plainly inflammatory and pyæmic. On post mortem the left anterior convolutions contained a decomposed focus the size of a nut; purulent foci were found in the lungs and uterus, with suppuration of the veins of the ovario-uterine plexus, \&c."

Although puerperal aphasia, apart from septic influences, is not common, I believe several cases of simple embolic aphasia during the puerperium are to be found on record. I can conceive no general condition of the blood more likely to predispose thrombosis and embolism than that found in pregnancy. At the same time, temporary absence or late appearance of murmurs cannot always be left out of count in valve lesions, as shown in Dr. Dickinson's very interesting paper on the "so-called Presystolic Murmur" in your present issue, so that some seemingly simple cases might be really complicated by cardiac conditions.

$$
\text { I am, Sirs, yours faithfully, }
$$

A. D. Lieith NAPIER, M.D.

Beaufort-gardens, S.W., Oct. 13th, 1887 .

\section{"IS CANCER CONTAGIOUS?"}

To the Editors of THE LANCET.

SrRs,--I have read with interest the annotation in your issue of the 8th inst. (p. 727) and Dr. Adam's letter published to-day (p. 766). If cancer were a contagious diseaseasing the term in its ordinary sense-such examples as those now cited would be very common instead of very rare. There is little doubt that cancer may be reproduced by direct implantation of small portions of the growth upon a suitable nidus (grafting). And the difficulties which attend the conditions essential to this method of propagation is the explanation of the rarity of the phenomenon. Mr. Hutchinson jun. related to me an instance in which a cancerous growth appeared upon the back of the hand, presumably caused by the implantation thereon of a portion of a similar growth from the patient's face. That the glans penis might become the seat of cancer from direct implantation of cells from a cancerous cervix uteri is possible, but the few examples recorded of penile and uterine cancer in man and wife, considered with the rarity of cancer of the penis and the great comparative frequency of uterine cancer strengthens my belief that if it ever be directly transmitted from one to another individual, the passage of cancer is effected by grafting - the process being comparable to the well-known surgical method of skin grafting. Therefore the interesting case of a member of our profession who, with his two wives, died of cancer, as described by Dr. Adam, should be regarded as a remarkable coincidence only. I am, Sirs, your faithful servant,

Chas. E. Jennings, F.R.C.S. Eng,

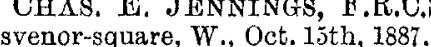

\section{To the Editors of THE LANCET.}

Sins,- With reference to the question of the contagiousness of cancer, I can mention two cases which somewhat bear out the idea of the possibility of such an occurrence.

In 1883 a man was admitted into the Liverpool Infirmary suffering from epithelioma of the penis. He stated that his wife had died some time before of cancer of the womb and he thought his complaint was something which he had contracted from her. He had never had any venereal disease. I can distinctly recall to mind the remark of the surgeon whose case it was, that we had no evidence that cancer could be so communicated.

The second case occurred in my practice a few months ago. In March, 1887, I was called to Mrs. E-_, and found ler suffering from uterine cancer, which had evidently been in existence at least some months; it being, in fact, too late then for any operative interference. This woman's husband had had his entire tongue removed for epithelioma in November, 1885. Both she and her friends were quite unaware of anything being wrong with the uterus. The cancer subsequently grew very rapidly, and she died in July last. The family history on both sides was good.

I am, Sirs, yours obediently,

Thos. G. Laslett, L.R.C.P. Lond., \&c.

Farnworth, Bolton, Oct. 19th.

\section{THE SMALL-POX OUTBREAK IN THE PERTH INFIRMARY. \\ To the Editors of THE LANCEx.}

Sins,--So much has been said and written about the recent outbreak of small-pox in the infirmary here, that it appears due to ourselves, our medical brethren, and the public to send you a short statement of the occurrence, and how it has been dealt with.

The disease showed itself in three female patients lying in the same ward at the beginning of this month. The medical officer in charge, while suspicious as to the nature of the affection and alive to the danger, was not quite sure of the diagnosis. On the 4th, a consultation of the staff was held, and suspicions fully confirmed. The local authority were informed of the outbreak, but their hospital was not in a fit state to receive patients. These were removed the following night, and even then cleaning and other work were still in progress. Next day three nurses were evidently attacked, and another female patient, who had been lying in No. 1 ward, showed suspicious symptoms. Immediate action was necessary. Women only had been seized, but men might, be any hour. The outbreak was a mystery, its future uncertain. A large detached building, erected in 1865 for infectious diseases, was seen to be available, and the sufferers were at once taken there. No. 1 (the ward affected) had been cleared of all patients not down with the disease on the day of its discovery, and thoroughly disinfected. All mattresses that had been in the ward were burned, bedding at once steeped in 1 in 20 carbolic acid, then boiled, and afterwards washed. One other nurse was seized with suspicious symptoms eight days after assisting in the removal of her colleagues to the west wing; and a fourth female patient was also attacked, and she too was at once taken there. $W \theta$ are quite satisfied that she has passed through an attack of small-pox, but so extremely milderuption only two or three aborting vesicles-that no one would have been justified in sending her to any hospital outside that in which she was serving. Fortunately for such a 
case, our infirmary has always had abundant available space for complete isolation. Three detached blocks provide accommodation for over 100 patients; very seldom fifty, rarely more than forty, patients are in the house at one time. Small-pox nurses were at once obtained from Edinburgh, and the most rigid quarantine enforced.

We were not prepared for such an occurrence; but this only led to a little extravagance in burning bed and body linen instead of washing it. There is a small kitchen belonging to the building, but no trustworthy cook could be hed at moment's notice. All food required, beyond what the nurses could prepare, has been taken to the door and placed in suitable vessels which never leave the infected building. The disease has not spread, and there is every reason to hope that it has been stamped out.

We are, Sirs, yours truly,

David H., STIRLING, M.D.

Consulting Physician and Surgeon, County and City of Perth Intirmary.

John T. GramaM, M.D., Visiting Surgeon, ditto.

LEIGH HUNT, M. B.

Perth, Oct. 25th, $1887 . \quad$ Visiting Officer, ditto.

\section{VACCINATION AND REVACCINATION.}

\section{To the Editors of THE LANCET.}

SIRs, - In connexion with the interesting discussion in your columns on the subject of vaccination, I have had a personal experience which perhaps you may consider worth publishing.

I was at a boarding school where there were about 160 pupils. Small-pox appeared; how it made an entry wa never very well cleared up. Within about a week thirteen boys became ill, and at the end of that time I myself became so unwell that I was no longer able to keep to $\mathrm{my}$ feet and was removed to that part of the College called the "infirmary," where the thirteen were already 1solated. On the same evening everyone-boys masters, and servants, with the exception of those who had been successfully revaccinated or had previously had small-pox--was vaccinated Whether all these vaccinations proved successful I cannot 9ay, The result, however, I can answer for. Not another case of small-pox occurred from the moment of this general vaccination, although the rest of the 160 boys were subject to exactiy the same influences as the fourteen who were attacked, excepting the revaccination. Of the fourteen, one died, and the remaining thirteen were all more or less badly marked about the face. I may mention that I had never been revaccinated, and the mark that remained from my first vaccination was scarcely perceptible. This experience has very strongly impressed me with the importance of vaccination or revaccination, as the case may be, even when small-pox has already appeared in a house.

I am, Sirs, yours truly,

ALFRED J. MACNALLY, B.A., M.B., \&c.

Kingstown, Oct. 22nd, 1887.

\section{TREATMENT OF SCARLET FEVER.}

\section{To the Editors of THE LANCET.}

SIRs,-I have for some years treated all my scarlet fever cases with, in addition to the ordinary treatment by salines, an application every day of 1 in 20 carbolic oil to the whole of the surface of the body. By this means $I$ have always been able to prevent the disease attacking others in the house, and I have noticed that all cases so treated from the beginning have done well. After the letter of Mr. Arthur Wiglesworth in your paper it occurs to $m \theta$ that the carbolic reid was in part ab"sorbed, and was an important agent in the well-doing of my patients.

I am, Sirs, your obedient servant,

Southeer, Oct.14th, 1887. ALbert BenthatL.

Spanish Congress for the Protection of Young CHILREN,-A Congress for the Protection of Young Children has recently held some meetings in Cadiz. The questions discussed included the establishment of hygienic schools with medical men as masters, the necessity of modifying the present system of education, the insufficiency of the support allowed by the State for children, and the regulation of the employment of children in factories and workshops.

\section{MANCHESTER. \\ (From our own Correspondent.)}

OWENS COLLRGE.

The Medical Societies have commenced work again for the winter. On the 12th inst., at the Pathological Society. Mr. Stocks was elected president for the coming year. In addition to the usual pathological exhibits, Dr. Dreschfeld gave a very interesting résumé of some experimental work he has been doing, bearing upon the bacterial origin of malignant endocarditis. He concludes that a streptococcus associated with this disease is the true pathogenic organism producing it. The Medical Society held its first meeting on Wednesday last, when several good surgical cases were exhibited. The entries at the College, though not yet complete, show that $O$ wens will again take the lead of the provincial medical schools, and probably not more than two or three of the metropolitan schools will exceed it in numbers. More than ninety students have been entered, of whom seventy have entered for the whole curriculum. Professor Young, the Dean, in his annual report, states that, "while there has been no diminution in the number of those presenting themselves for the degree of the University of London, the number of candidates for the Victoria University degree has largely increased." The appointment of Dr. Ross as joint lecturer on medicine with Dr. Morgan has given much satisfaction to the students. Sir Wm. Roberts and Sir H. Roscoe have been appointed Emeritus Professor of Medicine and of Chemistry respectively. It is in contemplation to present to Sir $\mathrm{Hy}$. Roscoe his portrait, as a token of respect and admiration from those who have been students under him in days gone by. Subscriptions will be received from any old "Owens man" by Dr. Thorpe, Science and Art Department, South Kensington.

THE EXHIBITION.

The success of our Jubilee Exhibition has been unparalleled, considerably more than four millions of persons having visited it. If any of your readers in this district have not examined the beautiful specimens of rare chemicals, alkaloids, and other allied substances, they will do well to do so ere the Exhibition closes. Space will only permit the bare mention by name of the beautiful cinchona alkaloids and barks shown by Messrs. Howard. Lactic acid (sp. gr. 1'21) for use as a caustic, nitrate of aconitine, bydrochlorate of apomorphine, pure atropine, berberine, salts of cafferine, camphor monobromide, tannate of cannabine, chrysarobin, salts of cocaine, colchicine, hydrastine, hyoscyamine, and many other rare and interesting active principles, are shown by Messrs. Merck; whilst Messrs. Christy and Co. have a large collection of the raw vegetable, plant, fruit, \&c, from which many of the foregoing are obtained. The chemical student will be interested in the rare metals, selenium and its salts, tellurium, cermanium, indium, gallium, \&c., shown by Dr. T. Schuchardt of Germany.

\section{ACCOMMODATION FOR INEECTIOUS CASES.}

The proposal to erect a new fever hospital at Hope on ground belonging to the Salford guardians has been vetoed by the Local Government Board, so the corporation will have to look elsewhere for a site. Seeing how large an open space exists at Monsall, where all small-pox cases from Salford are at present treated, it seems a pity that arrangements cannot be made with Manchester to receive all other infectious cases too. Owing to the continued prevalence of scarlet fever, the Monsall hospital has had considerable difficulty in finding room for all the patients admitted there, the total number under treatment at the present time being the largest since the hospital was established. Happily we have but little small-pox, but, seeing how frequent and extensive the communication with Sheffield is, where smallpox is now rife, it will not be surprising if more cases are met with.

If the ship canal scheme has done nothing else, it has wakened up our municipal authorities to take immediate steps to stop the pollution of the Irwell by sewage. Manchester is not only about setting her own house in order, but is taking energetic steps to compel all other offenders to do likewise.

Among the candidates for municipal honours at the ensuing elections for city councillors is one representative of the medical profession. Manchester at present, unlike 